\title{
BACHELARD E DELEUZE: (DES)CONTINUIDADES GEOFILOSÓFICAS
}

\author{
Gabriel Kafure da Rocha ${ }^{1}$
}

\begin{abstract}
RESUMO: O presente artigo procura investigar a noção de espaço em Bachelard e Deleuze, primeiramente trabalhando ontologicamente a noção de continuidade e descontinuidade de ambos filósofos, para então chegar a novos horizontes sobre o que é uma filosofia em que a terra, a casa e a arte se tornem paisagens para novas perspectivas do pensamento.
\end{abstract}

Palavras Chave: Imagem; Imanência; Desterritorialização; Diferença.

\section{Considerações iniciais}

Aparentemente, Bachelard e Deleuze parecem ter muito em comum, ambos têm uma maneira de filosofar oposta ao cartesianismo, assim como também se dirigem a importância do conceito na filosofia, colocando-o em suspeita na relação da objetividade, o empirismo e questionando sua posição entre a metafísica e a cientificidade. Contudo, há também uma problemática fundamental que os diferencia: suas noções de continuidade e descontinuidade. Ao passo que, para Deleuze, a continuidade vem de um ponto de vista da evolução e das relações com o futuro numa perspectiva temporal imanente; para Bachelard, a descontinuidade é justamente a possibilidade de quebrar o contínuo e criar o novo e que isso está implicado o âmbito das revoluções epistemológicas.

Isso não impede que haja o novo também em Deleuze, que em sua visão do emaranhado de linearidades há algo como possibilidades de união, também se vê uma forma de trazer o novo, de construir planos sobre planos e produzir espacialidades. Já para Bachelard, é a totalidade das descontinuidades que podem responder os diferentes problemas que surgem pela ciência e esta por si, como construção do fenômeno, constrói também novos espaços. No decorrer da consciência una entre espaço-tempo, a história da ciência teve que primeiramente quebrar cada um dos conceitos, espaço e tempo, para depois dialeticamente admitir sua indivisibilidade. $\mathrm{Ou}$ seja, arrancá-los do todo, para torná-los conhecidos.

\footnotetext{
${ }^{1}$ Doutorando em Filosofia pelo PPGFIL UFRN, Prof. de Filosofia do Instituto Federal do Sertão Pernambucano.
} 
O posicionamento de ambos os filósofos sobre essas questões diz respeito também ao contexto do que eles estavam tentando investigar e responder. Enquanto para Bachelard havia um interesse nas raízes metafísicas de uma necessidade dialética que tivesse como responder o poder das representações da transcendência, para Deleuze, a criação de uma nova perspectiva de pensamento que abarcasse um contexto pós-moderno era interessante para a própria continuidade da filosofia. "Deleuze está preocupado com questões de como a metafísica veio a alimentar a ilusão de identidades fundamentais e transcendentes e de como desenhar as condições virtuais e contínuas para estas ilusões." (WILLIAMS, 2005, p. 70).

Pode-se entender, nesse sentido, que Deleuze e Bachelard possibilitam novos caminhos de conciliar a relação entre transcedência e imanência na filosofia, no sentido de voltar suas filosofias principalmente a um equilíbrio ligado a terra. Desse modo, algumas aproximações dentro da perspectiva espacial e geofilósofica de ambos, delineiam noções e conceitos que vão desde a filosofia do animal até a crítica da estruturalidade do mundo, e com isso abrem espaço para uma espécie um pouco diferente de fenomenologia da casa e da paisagem.

\section{A continuidade}

Um primeiro problema deleuzeano pode levar abaixo o empreendimento dialético de Bachelard; a possibilidade de progresso. A ideia de progresso em Deleuze pode se atualizar dentro do contexto do eterno retorno e a diferença, desse modo o retorno apenas intensifica mais o progresso, é da noção de intensidade que se dá o novo. Mesmo sendo possível falar de progressos científicos, não é possível desvincular essa ideia da possibilidade de valor, afeto e sensibilidade. O fato é que diferentemente da ciência, a filosofia não é progressiva. E nisso se implica que para Bachelard a filosofia é uma fenomenologia na qual problemas bem colocados e pensados podem ser resolvidos.

Para Deleuze, a maneira como o novo se apresenta é uma expressão da sensibilidade e da intensidade, para ele, em cada diferença reside também uma continuidade transcendental da identidade. As diferenças são sobreposições de espaços, como bem argumenta em Diferença e Repetição. Por isso mesmo, o próprio eterno retorno, para Deleuze, é um retorno da diferença.

Esse é um retorno de diferentes intensidades e ideias que não podem ser relações em que há possibilidade de descontinuidade, pois todas as coisas estarão sempre de algum modo conectadas. Para Deleuze, a ideia do nada se daria então, justamente como uma indiferença, "A 
indiferença tem dois aspectos: o abismo indiferenciado, o nada negro, o animal indeterminado em que tudo é dissolvido, mas também o nada branco, a superfície da calma recuperada nas determinações flutuantes que não são ligadas" (Deleuze, 2006, p. 61).

Ora, Bachelard, contudo, entende que é justamente a ideia do nada, que na Dialética da Duraşão afirmou "O primeiro pensamento claro é o pensamento do nada" (Bachelard, 1994, p. 17), logo, esse é um dos principais argumentos contra a noção do continuísmo, pois se o ser, movimento, espaço e duração não tivessem lacunas, o nada não existiria, aliás, não haveria nem o não-ser como fronteira nadificante de tudo que é. Ainda assim, Bachelard também admite a ideia do eterno retorno em o "Ar e os sonhos", mas a maneira como ele vê essa questão tem a ver com uma possibilidade em espiral, ou seja, uma verticalização. Para Bachelard, em A dialética da duração, a fenomenologia e psicologia do tempo implicam em uma descontinuidade ontológica, posto que a continuidade é uma ilusão que possibilita a afirmação de uma atividade. Para ele, a noção de continuidade seria justamente uma não possibilidade atômica do vazio e do nada, ou seja, das interrupções que existem no campo espacial entre os objetos.

Se Bachelard entende que os julgamentos são justamente negativos e passíveis de erros por conta da descontinuidade, e isso é por demais importante na sua filosofia, pois o erro é fundamental para o progresso. Então Deleuze compreende que isso gera uma possibilidade na qual a ideia do transcendental acaba caindo num a priori ultrapassado do tempo.

Ambos os filósofos caminham para estabelecer a importância da experiência pessoal. Em Deleuze, a multiplicidade de sensações e intensidades são abstraídas como signos, noção de onde emergem todas as imagens. Nessa mesma linha de raciocínio, Deleuze tenta argumentar que na imagem podem existir pontos da descontinuidade, mas que nosso cérebro faz deles uma continuidade. A primeira dessa tendência cerebral diz respeito as repetições e variáveis, que do conceito da virtualidade da memória, são variáveis virtuais entre os aspectos do passado. Ou seja, mesmo que haja descontinuidade entre eventos do passado, a memória individual ou coletiva irá estabelecer um nexo de causalidade e continuidade entre os fatos.

Deleuze chama de seleção uma síntese da relação do tempo com o futuro, isso constitui uma continuidade também sobre a direção do novo como transformação do tempo. Apesar da seleção ser um corte do passado para um novo caminho, ainda assim constitui numa continuidade. Nesse ponto, justamente continuidade e descontinuidade estão implicadas na mesma seleção.

Isso leva também a um paradoxo que o tempo é ao mesmo tempo continuo e descontinuo. Realmente, essa possibilidade de simultaneidade não foi prevista por Bachelard. Logo, para Deleuze, é na repetição que se constitui uma estratégia de produção da memória, já na 
seleção do futuro como uma diferença com o passado é que há uma passagem do eterno retorno do diferente. " Gaston Bachelard opõe o problema ou objeto-portador do problema à dúvida cartesiana, e denuncia o reconhecimento de padrões em filosofia." (Deleuze, 2006, p. 216) Para Deleuze, o objeto portador é o conjunto de signos que vem ao encontro do objeto, a imagem como tal, uma vez que é possibilidade de superar a dúvida cartesiana. Já quanto a noção de problema, pode-se dizer que

A fundamentação da noção de 'problema', para Deleuze, liga-se à différence. Os 'problemas' não são um estado provisório e subjetivo pelo qual nosso conhecimento deveria passar devido às suas limitações. [...] $O$ 'problema' enquanto tal é totalmente determinado e diferenciado, embora ainda não resolvido. Essas 'ideias-problemas' se apresentam num estado sob o nome de perplicação, com suas multiplicidade e variedade coexistentes, suas determinações de elementos e formações de séries ideais em torno de singularidade móveis. (FELÍCIO, 1994, p. 18).

Felício sugere que o dinamismo da 'polêmica' ou do 'problema' entre ambos os filósofos tem como resolução a ipseidade entre a vontade e o entendimento. Daí se dá a dinâmica imanente do pensamento independente da continuidade ou ruptura. A diferença é para Deleuze a descontinuidade, na medida em que as séries heterogêneas do pensamento de um sistema diferenciador é abolir a identidade e semelança.

\section{A (des)continuidade e a imagem}

A imagem, para Bachelard, a imagem é um acontecimento ${ }^{2}$ que transcende a visualização. Ela pertence propriamente ao domínio da imaginação, mais do que a visão. Imagem, lembrança e memória escapam à história e a psicologia

Todo lance de memória é solidário a uma esquematização que, datando os acontecimentos, isola-os. Esvazia-os de sua duração para lhes dar um lugar preciso. Essa esquematização é como um esboço da exposição racional, como um plano de desenvolvimento para a narração de nosso passado. Esse plano acredita ligar os fatos entre eles; na verdade, ele os separa. Por exemplo, ao mostrar que dois acontecimentos estão em sequência lógica, a narração comprova que o segundo é produzido por uma conduta adiada a partir do primeiro. (BACHELARD, 1988. p. 50).

Enquanto Bachelard direcionava a sua obra $A$ dialética da duração a uma crítica direta a Bergson, sabe-se que Deleuze dedicou sua filosofia e escreveu até um livro chamado Bergsonismo. Contudo, o intuito de Bachelard, em sua crítica a Bergson, foi talvez tentar aplicar a ideia de

${ }^{2}$ É interessante que segundo ZOURABICHVILI (2004) a ideia de acontecimento em Deleuze é justamente como o instante, no sentido de que é o momento presente da efetuação e a fronteira entre todo o tempo. 
descontinuidade na própria continuidade. Ou seja, tentar justamente o intento oposto de Deleuze.

Nesse sentido, é possível destacar entre os argumentos bachelardianos que a realidade dos métodos científicos não precisam da continuidade, pois elas emergem da relação entre preenchimento e vazio, aproximação espacial da verdade e erro. A ação que pressupõe a necessidade da descontinuidade é então que a continuidade (como verdade) é mecânica, ao passo que todo mecanicismo por falhar.

$\mathrm{Na}$ busca por uma organicidade, Bachelard entente que o tempo pode e deve ser dividido para ser ordenadamente observado. Enquanto a física mostra que a realidade é descontínua, a psicologia mostra que a continuidade também é fruto de um processo temporal da descontinuidade entre passado e futuro.

Mas e o presente? Essa é justamente a radicalidade do instante presente. De modo que, para Bachelard, a continuidade bergsoniana e consequentemente deleuziana do tempo é uma forma de hesitação. O presente é a novidade, que desenha como o sujeito se reformula numa relação mais relacional com o objeto. De forma que objeto e sujeito se constroem mutuamente nessa relação.

Tal empreendimento parece se distanciar da teoria deleuziana, pois a continuidade implicaria justamente numa indiferenciação com o objeto. Isso demonstra como o tema não se esgota e a partir de então pretendo fundir os horizontes entre ambos os filósofos e adentrar justamente na perspectiva do espaço e paisagem.

\section{Casa e território}

O território são os limites de um determinado pensamento, momento. Isso não faz com que ele seja mutável, mas o caos em que ele está inserido, após sua desterritorialização da sua imagem da continuidade, é possível então reterritorializar e construir então uma casa como apropriação e subjetivação centrada em si. É interessante que para Deleuze e Guatarri, a casa é uma manifestação primitiva, ela começa propriamente com a animalidade e seus casulos.

A concha, como casa do molusco, se torna, quando ele morre, o contraponto do Bernardo-eremita que faz dela seu próprio habitat, graças a sua cauda que não é nadadeira, mas preênsil, e lhe permite capturar a concha vazia. $O$ Carrapato é organicamente construído de modo a encontrar seu contraponto no mamífero qualquer que passa sob seu galho, como as folhas de carvalho arranjadas como telhas, nas gotas de chuva que escorrem. Não é uma concepção finalista, mas melódica, em que não mais sabemos o que é arte ou natureza ("a técnica natural") (DELEUZE, 1992, p. 239). 
Sim, a casa é um conceito rico, e pode ser deformado na medida em que é vista como manifestação natural. Pode-se dizer até que o cérebro é a casa da mente humana ou vice-versa, a organização desse espaço é fundamental para filosofar. Ora, há aí também uma relação fundamental com Bachelard, que em a Poética do Espaço dedica um capítulo todo a examinar o complexo desses tipos de habitação. A ostra, para o filósofo, representa justamente o processo lento da feminilidade da formação contínua e fértil. Já em Lautreamont, obra que Bachelard se dedicou a crítica literária do Conde Isadore Ducase, ele cita como parte do bestiário piolhos, aranhas, sanguessugas. Ou seja, são animais que ilustram rupturas. Fragmentadas em situações de simbiose e agressão com os hospedeiros.

Mas voltando ainda a questão da casa como animalidade, Bachelard diz que o refúgio é uma forma de se encolher, esconder e se ocultar sobre si. Esse seria o indício de uma psicologia primitiva, na busca da segurança do ninho perfeito. A árvore, a casa alegre, são ninhos vigorosos para quem as sabe habitar. É o limiar entre a proximidade e distância, continuidade e descontinuidade.

Os sonhos da casa-vestimenta não são desconhecidos daqueles que se comprazem no exeracio imaginário da função de habitar. Trabalhando a morada da mesma maneira que Michelet sonha com o ninho, estar-se-ia revestido de uma vestimenta de confecção, tão freqüentemente marcada de um signo mau por Bergson. Ter-se-ia a casa pessoal, o ninho de nosso corpo, feito à nossa medida. (BACHELARD, 1993, p. 263).

O ninho é a imagem que está entre o mundo e o homem. A ideia do corpo parece ser uma continuidade e aproximação com a desterritorialização empreendida na ciência por Deleuze e Bachelard. Ora, não há mais sujeito, então só há corpo. A ideia da casa como espaço vivido ou sistema percebido conota o fato de que apenas os filósofos e artistas habitam seus conceitos, e habitar o seu próprio corpo como conceito-casa é um ethos possível e necessário. Ainda assim, Deleuze e Guatarri parecem empreender uma visão abstrata sobre a casa, colocando-as novamente na visão dos planos que territorializam o espaço.

O que define a casa são as extensões, isto é, os pedaços de planos diversamente orientados que dão à carne sua armadura: primeiro plano e plano-de-fundo, paredes horizontais, verticais, esquerda, direita, retos e oblíquos, retilíneos ou curvos... Essas extensões são muros, mas também solos, portas, janelas, portas-janelas, espelhos, que dão precisamente à sensação o poder de manter-se sozinha em molduras autônomas. São as faces do bloco de sensação. (DELEUZE, 1992, p. 232).

A casa parece determinar a primeira estrutura ou lugar do avistamento da paisagem. O plano de imanência na seu horizonte pré-filosófico, na medida que se territorializa o terreno, talvez se habite, contudo, só depois de desterritorializar, abandonar esse terreno é que leva a destinação inevitável do conceito. 
Há espaços e tempos múltiplos com regiões movediças que na "relação 'aqui-horizonte' que 'exclui toda sistematização do espaço'; nenhum ponto de vista, nenhuma regra, mas um horizonte que se transforma continuamente" (SANTOS, 2013, p. 107).

Por encerrar então, a paisagem se mostra como quando o distante se torna próximo, é a natureza inumana instalada e habitada pelo homem. Para Bachelard, a paisagem é o espaço da ação da imaginação que trabalha pelo dinamismo da vontade que acumula os elementos da natureza sem negar a sua violência da habitação (tal como era o caso do carrapato, piolho, etc). É uma construção por uma simpatia, não da imagem em si, mas da vista que ela pode dar para a filosofia.

Em O direito de sonhar, Bachelard escreve um capítulo chamado Introdução a dinâmica da paisagem, nele, a paisagem é um estado da alma, assim como a casa. A "paisagem do filósofo, a paisagem pensada, é plana, sistematicamente plana, gloriosa às vezes por ser plana. Estranha dominação metafísica do mundo, que não toma consciência de si senão quando o mundo está longe, diminuído, empalidecido, negado, perdido!” (BACHELARD, 1994, p. 57)

Para Deleuze, a paisagem vê e nós não temos memória sobre a paisagem. Esta é como um sonho invisível que se torna visível num instante como o sentir. Logo, conquistar as paisagens é se perder nelas e abandonar as determinações temporais, espaciais e objetivas.

\section{Considerações Finais}

Em uma imagem alegórica, em que medida a água no gelo é água e o gelo na água é gelo? Esse é um limite difícil de entender no plano filosófico de Deleuze \& Guatarri e os tênues problemas das substancialidades espaciais. Água e gelo, é, pois, como um fractal, em que ondas infinitas de energia vão se dispersando e se diferenciando num mesmo todo, e esse é certamente um encontro com a visão de Bachelard. Visto que, para ele a matéria é justamente uma qualidade secundária da energia vibratória, que se dá por ondulações em que há um "materialismo ondulatório" (Cf. QUILLET, 1967, p. 130)

Contudo, mais do que desconstruir a relação entre a substancialidade da relação sujeitoobjeto, Deleuze e Guatarri insistem que "O sujeito e o objeto oferecem uma má aproximação do pensamento. Pensar não é nem um fio estendido entre um sujeito e um objeto, nem uma revolução de um em torno do outro. Pensar se faz antes na relação entre o território e a terra." 
(Santos, 2013, p. 113). Pensar é se posicionar, nesse sentido, ambos os filósofos nos convidam a se posicionar no agon entre continuidade e descontinuidade. É nesse horizonte que é preciso entender as perspectivas metafísicas que se conjugam entre a imanência e a transcendência do que é a filosofia.

É que as figuras são projeções sobre o plano, que implicam algo de vertical ou de transcendente; os conceitos, em contrapartida, só implicam vizinhanças e conjugações sobre o horizonte. Certamente, o transcendente produz por projeção uma "absolutização da imanência" (SANTOS, 2013, p. 121).

Ora, esse é um aspecto extremamente complexo da continuidade da imanência, já que ela parece abarcar também a transcendência. Contudo, apesar de Deleuze e Guatarri se posicionarem como superadores do método fenomenológicos, eles admitem nessa perspectiva espacial imanente, uma espécie de poética nos dá uma paisagem não-científica suportada fenomenologicamente. "há também conceitos não-científicos, que suportamos em doses homeopáticas, isto é, fenomenológicas.” (DELEUZE, 1992, p. 189).

Nesse sentido homeopático, Bachelard acredita que há uma transmutação dos valores ontológicos e fenomenológicos que necessitam de uma verticalidade, uma direção do espírito que rompe com a imanência, esse é o ser humano, o filósofo que pensa, inventa conceitos e imagina "sabe-se que filosofia, no pensamento de Bachelard [...], é coisa de imaginação." (QUILLET, 1967 p. 146).

Nesse sentido, se consagra uma aproximação entre o que Deleuze e Guatarri estruturaram como: arte (monumento) de blocos de sensações, planos de composições e figuras estéticas; ciência (estado de coisas), funções, planos de referências e prospectos; filosofia (acontecimento), do conceito, plano de imanência e personagens conceituais. Ora, é nessa relação que a arte e a imaginação fogem de qualquer conceituação, compondo o não-filosófico necessário a filosofia. É aí que se dá a complementariedade fundamental, as obras e/ou monumentos infinitos que se conceitualizam pela filosofia por esses filósofos trabalhados nessa quiasma entre ser, sujeitoobjeto e linguagem que se manifestam na nossa casa mental/cerebral.

O termo 'diferença' é empregado por Deleuze enquanto ligado às 'série heterogêneas' de um sistema; e o 'diferenciador' é o precursor que age proposcionando a diferenciação das 'diferenças' e que abole a identidade e a semelhança. Essa noção pode ser ligada à de 'dialética dinâmica' em Bachelard, terminando por relacionar 'poética e ciência' na medida em que se unem pela diferença, isto pe, 'co-existem como dois contrários bem feitos'. (FELÍCIO, 1994, p. 10).

Desse modo, no desafio cerebral de encontrar as aproximações entre ambos os filósofos, descobrimos as felizes diferenças que dinamizam as nossas próprias noções de admitir que há 
esclarecimentos maiores a serem feitos entre as questões de imanência, continuidade e diferença. Para isso, se exige uma investigação maior sobre o próprio Bergson.

Por fim, repetir é interrogar os outros pensadores? o que há de novas elaborações, o dialogar ser respondido de modos diferentes. É preciso preencher e esvaziar os espaços no sentido de mantê-los abertos para outras visitações ou habitações. É como se fosse uma espécie de territorialização e desterritorialização, porém sem reterritorializar. Essa é uma diferença fundamental da imanência continuísta que visa ocupar todo o desabitado, contudo, o nada deve permanecer sempre desabitado numa dialética negativa e aberta e dinâmica.

\section{REFERÊNCIAS}

BACHELARD. A poética do Espaço. 2. ed. Tradução de Antonio de Pádua Danesi. São Paulo: Martins Fontes, 1993.

A dialética da duração. Tradução: Marcelo Coelho. $2^{a}$ ed. São Paulo: Ática, 1994. . O direito de sonhar. Rio de Janeiro: Bertrand Brasil, 1994.

2007.

. A intuição do instante. Trad. Antônio de Padua Danesi. Campinas, SP: Verus Editora,

DELEUZE, Gilles; GUATTARI, Felix. O que é a filosofia? Trad. Bento Jr. E Alberto Alonso Muñoz. Rio de Janeiro: Ed. 34, 1992.

Diferença e repetição. Trad. L. Orlandi e R. Machado. Rio de Janeiro, RJ: Graal, 2006.

FELÍCIO, Vera. A imaginação simbólica. São Paulo: Fapesp, 1994.

SANTOS, Zamara. A geofilosofia de Deleuze e Guatarri. Tese (doutorado) - Universidade Estadual de Campinas, Instituto de Filosofia e Ciências Humanas. Campinas, SP : [s. n.], 2013.

WILIIAMS, James. The transversal thought of Gilles Deleuze: encounters and influences. Manchester: Clinamen Press, 2005.

ZOURAVICHVILI, François. O vocabulário de Deleuze. Trad. André Telles. Rio de Janeiro: Unicamp, 2004. 